\title{
ESTUDO DO CLIMA ORGANIZACIONAL NO SETOR INDUSTRIAL
}

\author{
STUDY OF ORGANIZATIONAL CLIMATE IN INDUSTRIAL ORGANIZATIONS
}

Recebido em 12.07.2015. Aprovado em 16.11.2016

Avaliado pelo sistema double blind review

DOI: http://dx.doi.org/10.12712/rpca.v10i4.698

\section{Fabiana Pinto de Almeida Bizarria \\ bianapsq@hotmail.com \\ Universidade de Fortaleza, Fortaleza/CE, BRASIL}

\section{Ana Zenilce Moreira}

anamoreira.ead@gmail.com

Universidade Estadual do Ceará (UECE), Fortaleza/CE, BRASIL

\section{Márcia Zadbdiele Moreira}

marciazabdiele@gmail.com

Universidade Federal do Ceará (UFC), Fortaleza/CE, BRASIL

\section{Alexandre Oliveira Lima}

alexandrelima@unilab.edu.br

Universidade da Integração Internacional da Lusofonia Afro-Brasileira (UNILAB), Redenção/CE, BRASIL

\section{Resumo}

Estudar clima organizacional revela-se como um mecanismo para conhecer a organização e o ambiente de trabalho e, assim, propagar aos dirigentes uma visão mais abrangente da organização e não apenas uma simples interpretação de dados (RIZZATTI, 2002). O estudo objetivou analisar os fatores de clima organizacional em uma indústria de cosméticos localizada na Região Metropolitana de Fortaleza. O instrumento de pesquisa utilizado foi aplicado a 209 colaboradores da empresa e possui 35 itens associados a uma escala de amplitude de 4 pontos. Para análise e interpretação dos dados foi realizada análise multivariada de dados, Análise Fatorial Exploratória, com suporte do software denominado Statistical Package for the Social Sciences, (SPSS), versão 20. Foram identificados e definidos 6 fatores, de forma decrescente, são eles: Papel do líder; Coesão entre colegas; Suporte físico e material; Bem-estar no trabalho; Poder e Hierarquia e Respeito a diversidade. Concluiu-se que, na organização estudada, espera-se que o líder assuma papel diretivo, o que é compreensível no contexto de trabalho industrial. Além disso, anseia-se por relações horizontais, em que os cargos não influenciem as interações sociais. O suporte físico e material, representado, pelo uso de equipamentos em condições satisfatórias é também indicativo de clima organizacional. Sentir-se acolhido pela empresa é fator de bem-estar. Além disso, a hierarquia e o exercício do poder informa que a relação líder-liderado pode produzir um ambiente aversivo, quando a "equação" trabalhador-líder/chefe-organização não está bem estruturada. Por último, o aspecto da diversidade é apontado, e sugere que a gestão do clima deve ir além dos aspectos relacionados à gestão do trabalho em si, mas é importante incorporar que as manifestações humanas se façam presentes no ambiente laboral. A identificação do conjunto de fatores merece maior aprofundamento teórico, de forma que as 
definições possam ser refletidas conceitualmente. O reporte a teoria limitou-se ao levantamento de dimensões em diversos modelos, sem que a pretensão fosse abranger todo o clima organizacional, mas a apreensão mais sistemática do fenômeno.

Palavras-chave: Clima organizacional. Percepção. Pesquisa de clima.

\section{Abstract}

Studying organizational climate turns out like a mechanism to know the organization and its work environment and thus propagate to leaders a vision organization more comprehensive and not just a simple data interpretation. This study aimed to analyze the organizational climate factors in a cosmetics industry located in the metropolitan area of Fortaleza. The research instrument was applied to 209 employees of the company and has 35 items associated with a range of range of 4 points. For analysis and interpretation of data was performed multivariate data analysis, Exploratory Factor Analysis, with software support called Statistical Package for Social Sciences (SPSS) version 20 have been identified and defined six factors, in decreasing order, they are: Role of leader; Cohesion among colleagues; Physical and material support; Well-being at work; Power and hierarchy and respect diversity. In conclusion, the study organization, is expected to assume the leading managerial role, which is understandable in the industrial working environment. In addition, longs up by horizontal relations, where the positions do not influence social interactions. The physical and material support rendered by the use of equipment in satisfactory condition is also indicative of organizational climate. Feeling welcomed by the company's wellness factor. In addition, the hierarchy and the exercise of power reports that the leader-led relationship can produce an aversive environment when the "equation" worker-leader / chief organization is not well structured. Finally, the aspect of diversity is pointed out, and suggests that climate management must go beyond the aspects of labor management to itself, but it is important to incorporate that human manifestations to be present in the work environment. The identification of the set of factors deserve greater theoretical depth, so that the settings can be reflected conceptually. The reporting theory was limited to the dimensions of survey in different designs without the intention was to cover the whole organizational climate, but a more systematic grasp of the phenomenon.

Keywords: Organizational culture. Perception. Climate research. 


\section{Introdução}

Intensas transformações de teor econômico, técnicocientífico, político e cultural vêm ocorrendo nas últimas décadas em todo o mundo, afetando de modo significativo a estrutura, a organização e o funcionamento das organizações. Esse cenário de mudanças exige esforço cognitivo e competências diversificadas (BISPO, 2006; RODRIGO; NASCIMENTO; NEIVA, 2014).

A indústria brasileira de higiene pessoal, perfumaria e cosméticos, como lócus da pesquisa, apresentou um crescimento médio deflacionado composto próximo a 10\% ao ano nos últimos 18 anos. Esse crescimento do setor se deve a vários fatores tais como: acesso das classes $\mathrm{D}$ e $\mathrm{E}$ aos produtos do setor, devido ao aumento da renda; novos integrantes da classe C passaram a consumir produtos com maior valor agregado; participação crescente da mulher brasileira no mercado de trabalho; utilização de tecnologia de ponta e o consequente aumento da produtividade, favorecendo lançamentos constantes de produtos que atendem cada vez mais às necessidades do mercado e o aumento da expectativa de vida (ABIHPEC, 2014).

Devido às mudanças, as empresas tem investigado a dinâmica da vida organizacional, buscando identificar como trabalhadores expostos a uma série de estímulos procedentes da organização e do ambiente de trabalho têm percepções similares e atribuem significados semelhantes aos aspectos importantes da vida organizacional (SIQUEIRA, 2008).

O clima organizacional representa uma variável que interfere no desenvolvimento do comportamento humano em prol da efetividade (TORRES; OLIVEIRA, 2007). Esse assunto ganhou enfoque científico no século XX, mais especificamente nos anos 1970, com o objetivo de identificar suas propriedades por meio de categorias, componentes e indicadores. Antes, as pesquisas eram de caráter geral e muitas vezes implícitas, como o estudo realizado por Maslow (1954). Desse modo, com a ampliação das pesquisas sobre aspectos do comportamento organizacional, as empresas tem dado maior atenção a essa temática.

Clima organizacional é um conceito importante para descrever as percepções das pessoas em relação à organização e ao seu ambiente de trabalho, afetando o comportamento e as atitudes das pessoas neste ambiente (RIZZATTI, 2002; MARTINS et al, 2004). Nesse sentido, percepção é o processo pelo qual organizamos e interpretamos as impressões sensoriais, dando sentido ao mundo que nos cerca (ZANELLI; SILVA, 2008). Ademais, as características de quem percebe, do alvo percebido assim como as características situacionais influenciam as percepções de cada um. Portanto, nas organizações de trabalho, as ações humanas sempre estão baseadas na percepção da realidade - o mundo percebido - e difere de pessoa para pessoa.

Conforme Schneider (1975), o clima organizacional se define na caracterização de procedimentos e práticas do ambiente organizacional, com a ocorrência de acordos entre as partes que compõem este ambiente. Representa um conceito relacionado aos níveis de satisfação no trabalho experimentado pelo empregado que tenta avaliar suas percepções acerca de elementos ou fatores presentes em seu ambiente de trabalho e que permitem o atendimento de suas necessidades (CODA, 1997). Assim, é uma tendência de percepção favorável ou desfavorável em relação ao trabalho em geral ou, então, em relação a diferentes aspectos ou variáveis que formam o clima na empresa.

A pesquisa de clima organizacional apresenta-se como uma ferramenta utilizada em processos de planejamento de estratégias de gestão, buscando mobilizar ações em prol da melhoria no ambiente de trabalho (SANTOS; NEIVA; ANDRADE-MELO, 2013). É uma prática difundida nas empresas, devido à abrangência teórica do construto e à capacidade de avaliar características complexas tais como: liderança, relacionamento interpessoal, reconhecimento, recompensa, entre outras, com base nas percepções dos trabalhadores da organização (MENEZES; GOMES, 2010).

Tendo em vista uma melhor compreensão sobre o assunto, este estudo tem como questão de partida a seguinte indagação: quais categorias influenciam o clima organizacional em um contexto industrial? De forma geral objetiva-se identificar os fatores de clima organizacional em uma indústria de cosméticos e, de forma específica, objetiva-se analisar esses fatores, como forma de explicar o clima organizacional e identificar as variáveis mais relacionadas aos fatores identificados.

A justificativa desta pesquisa está em consonância com as afirmativas de Rizzatti (2002) na qual defende que estudar clima organizacional revela-se como um mecanismo para conhecer a organização e o ambiente de trabalho e, assim, propagar aos dirigentes uma 
visão mais abrangente da organização e não apenas uma simples interpretação de dados (RIZZATTI, 2002). Sob esse ponto de vista, o estudo do clima organizacional, seja por meio do estudo das percepções ou das aspirações dos indivíduos, é um diagnóstico da instituição, especialmente pelo seu valor prático na adoção de novas estratégias administrativas.

O presente estudo está estruturado com os seguintes elementos: Introdução com a apresentação dos propósitos da pesquisa, seguido de referencial teórico sobre os conceitos e evolução conceitual de Clima Organizacional, bem como os principais Modelos de Clima Organizacional. Posteriormente, foram apresentados os procedimentos metodológicos utilizados, os Resultados obtidos, as Considerações finais e Referências.

\section{Clima Organizacional}

Os trabalhadores tem destinado parcelas cada vez maiores do seu tempo ao trabalho. Por meio do trabalho o homem obtém sua fonte de sobrevivência e realiza suas aspirações e objetivos pessoais, com referência nas percepções e significados atribuídos aos aspectos da vida organizacional (SCHNEIDER, 1985; CHANLAT, 1996; LUZ, 2001). As organizações representam a mediação entre o homem e o trabalho, adquirindo importante papel no cotidiano das pessoas.

Considera-se que o conceito de Clima Organizacional tem sua origem na pesquisa de Lewin, Lippitt e White (1939), quando afirma que há interação entre a dimensão pessoal subjetiva com aspectos do ambiente organizacional, traduzido como um ambiente psicológico. Em seguida, as pesquisas avançaram na concepção sobre clima, abrangendo outros aspectos como influenciadores do comportamento organizacional, como a esfera das relações sociais, componentes organizacionais e fatores situacionais (PAYNE; PUGH, 1976; MARTINS et al, 2004).

A evolução conceitual conduz a leitura de que o tema teve maior repercussão acadêmica a partir dos anos de 1990, embora a definição se apresentasse, ainda, de forma imprecisa e sobrepondo-se a definição de clima psicológico, satisfação no trabalho e cultura organizacional (TAMAYO, 1999). A busca pela demarcação entre os fenômenos situou que o clima organizacional é representado por elementos cognitivos e clima psicológico por elementos afetivos
(JAMES; JONES, 1974; SCHNEIDER; REICHERS, 1983; SIQUEIRA, 2008). Além disso, pesquisas posteriores fundamentaram que satisfação indica um posicionamento avaliativo do trabalhador em relação ao seu trabalho e cultura, envolve a compreensão e o compartilhamento de valores e normas e suscitam a elaboração de ações organizacionais (TAMAYO, 1999; TORO, 2001).

O clima organizacional é um conceito importante para compreensão do modo como o contexto do trabalho afeta o comportamento e as atitudes das pessoas nesse ambiente, sua qualidade de vida e o desempenho da organização e corresponde a um dos atributos mais importantes à revelação dos elementos reguladores e orientadores do comportamento humano dentro de organizações. Além disso, está diretamente relacionado com o estudo das percepções que os trabalhadores constroem acerca de diferentes aspectos do seu trabalho (SIQUEIRA, 2008; MENEZES; GOMES, 2010).

Uma das formas para melhor compreender a definição de clima organizacional é considerar algumas de suas propriedades, seja por meio do estudo de aspectos conceituais, ou da análise e da identificação de categorias com seus componentes e respectivos indicadores que possam contribuir com a elaboração de modelos específicos para sua análise em determinadas organizações (RIZZATTT, 2002).

O clima organizacional é considerado como o vínculo conceitual entre o nível individual e o nível organizacional, no sentido de expressar a compatibilidade ou adequação das expectativas, valores e interesses individuais com as necessidades, valores e condutas formais (PAYNE; MANSFIELD, 1973).

Por representar um instrumento de diagnóstico dos fatores significantes para a organização, a pesquisa de clima organizacional é uma ferramenta utilizada para o planejamento de estratégias de gestão de pessoas visando à melhoria no ambiente de trabalho.

Antes de iniciar a coleta de dados, é preciso esclarecer os colaboradores acerca da finalidade e a importância da pesquisa de clima organizacional, bem com ressaltar a importância da sinceridade nas respostas a fim de que seja possível obter os dados mais fiéis possíveis que expressem o nível de relacionamento entre a empresa e os seus funcionários (BISPO, 2006). Ademais, a solução de cada problema depende de sua gravidade; dos recursos necessários para a solução, tais como: os recursos financeiros, materiais, humanos 
e o fator tempo; do relacionamento do problema encontrado com outros problemas detectados e a sua solução conjunta; do esforço conjunto e da confiança mútua entre a empresa e seus funcionários para a solução destes problemas; além da capacidade dos administradores em encontrar boas soluções para os mesmos (BISPO, 2006).

O entendimento sobre clima organizacional pode ocorrer por meio de quatro perspectivas: abordagem estrutural, perceptual, interativa e cultural, conforme quadro 1.

Quadro 1. Abordagens do Clima Organizacional

\begin{tabular}{|l|l|}
\hline Abordagem & \multicolumn{1}{|c|}{ Clima Organizacional } \\
\hline Estrutural & $\begin{array}{l}\text { O clima surge a partir da percepção } \\
\text { de aspectos organizacionais tais como: } \\
\text { o tamanho, a divisão hierárquica, } \\
\text { centralização, tipo de tecnologia } \\
\text { empregada e regras de controle do } \\
\text { comportamento. }\end{array}$ \\
\hline Perceptual & $\begin{array}{l}\text { O clima organizacional tem relação } \\
\text { com o indivíduo, que assume o papel de } \\
\text { protagonista no processo de construção } \\
\text { desse clima, cujos elementos de base } \\
\text { são constituídos pelas suas percepções, } \\
\text { sejam elas aperfeiçoadas ou não. }\end{array}$ \\
\hline Interativa & $\begin{array}{l}\text { Nessa perspectiva são considerados, } \\
\text { além do indivíduo e os procedimentos } \\
\text { internos, os processos de interação, } \\
\text { seja entre os indivíduos da organização } \\
\text { como as interações entre os membros e } \\
\text { o cenário organizacional em que fazem. }\end{array}$ \\
\hline \multirow{5}{*}{ Cultural } & $\begin{array}{l}\text { Propõe o acréscimo das variáveis } \\
\text { culturais à abordagem interativa e tem } \\
\text { como ponto convergente a forma como } \\
\text { os indivíduos percebem, interpretam } \\
\text { e constroem a realidade, processo que } \\
\text { segundo a autora é permeado pela } \\
\text { cultura organizacional. }\end{array}$ \\
\hline
\end{tabular}

Fonte: Adaptado de Puente-Palácios (2003)

O clima reproduz o grau de satisfação material e emocional das pessoas no trabalho, influencia profundamente a produtividade do indivíduo e, consequentemente da empresa. Desse modo, o mesmo deve ser favorável e proporcionar motivação e interesse nos colaboradores, além de uma boa relação entre os funcionários e a empresa (LUZ, 2001).
No momento em que a organização estabelece como objetivo a busca da melhoria constante do clima organizacional, este foco se multiplica em várias direções da gestão e pode ser a base de sustentação da melhoria dos resultados da confiabilidade dos processos e equipamentos, os quais gerarão uma maior quantidade de micro-atitudes e micro-resultados, por parte da força de trabalho, inter-relacionadas aos resultados de cada equipe e juntas poderão modificar o resultado global da organização industrial moderna (RUCHINSKI, 2006).

Estudar clima organizacional revela-se como um mecanismo para conhecer a organização e o ambiente de trabalho e, assim, propagar aos dirigentes uma visão mais abrangente da organização e não apenas uma simples interpretação de dados (RIZZATTI, 2002). Sob esse ponto de vista, o estudo do clima organizacional, seja por meio do estudo das percepções ou das aspirações dos indivíduos, é um diagnóstico da instituição, especialmente pelo seu valor prático na adoção de novas estratégias administrativas. Para haver uma gestão do clima organizacional, é importante que as mudanças sejam realizadas a partir do diagnóstico e, ao mesmo tempo, que os trabalhadores percebam as modificações implantadas, visto que a pesquisa é apenas uma das etapas da gestão de clima (SANTOS; NEIVA; ANDRADE-MELO, 2013).

\section{Modelos de estudo do clima organizacional}

Pesquisas sobre o tema revelam a complexidade de sua abordagem diante da multiplicidade de modelos teóricos. Além disso, o percurso conceitual de suporte aos estudos indicam que o clima organizacional é um tema multidimensional, revestido de dimensões que compõe argumentos singulares, completares e que, por veze, se sobrepõe. Em geral, o estudo do clima faz uso de instrumentos que objetivam realizar "um levantamento de opiniões que caracteriza uma representação da realidade organizacional consciente." (CODA, 1997, p. 99). Os modelos mais disseminados na literatura são: Modelo de Litwin e Stringer (1968); Modelo de Schneider (1975); La Follete; Sims (1975); Modelo de Sbragia (1983); Modelo de Kolb et. al. (1986); Modelo de Rizzatti (1995); Modelo de Coda (1997); Modelo de Colossi (1991); Modelo de Rubbo (2002); Modelo de Martins et al (2004) Modelo de Bispo (2006).

Cada modelo possui seu escopo teórico que valida suas dimensões como explicativas para o constructo 
clima organizacional. Embora as nuances de cada modelo, há convergência de sentido entre dimensões que exploram aspectos organizacionais similares. Essa constatação suscitou a busca por dimensões representativas do fenômeno, que são levantadas no quadro 2.

Quadro 2 . Dimensões do Clima Organizacional mais presentes na literatura.

\begin{tabular}{|c|c|c|}
\hline Dimensões & Significado & Modelos \\
\hline Conforto físico & $\begin{array}{l}\text { Ambiente físico que proporciona conforto e recursos } \\
\text { suficientes para a execução das tarefas e ambiente } \\
\text { confortável. }\end{array}$ & $\begin{array}{l}\text { Modelo de Litwin e Stringer } \\
\text { (1968); de Schneider (1975); de } \\
\text { Bispo (2006); Colossi (1991); } \\
\text { de Martins et al (2004) }\end{array}$ \\
\hline $\begin{array}{l}\text { Reconhecimento e } \\
\text { Valorização }\end{array}$ & $\begin{array}{l}\text { Avalia a percepção quanto ao adequado reconhecimento por } \\
\text { trabalhos bem executados; o reconhecimento alinhado a boa } \\
\text { qualidade do trabalho. }\end{array}$ & $\begin{array}{l}\text { Modelo de Coda (1997); de } \\
\text { Rubbo (2002); de Coda (1997) }\end{array}$ \\
\hline $\begin{array}{l}\text { Coesão entre } \\
\text { colegas }\end{array}$ & União, vínculos e colaboração entre colegas de trabalho. & $\begin{array}{l}\text { Modelo de Litwin e Stringer } \\
\text { (1968); de Coda (1997); de } \\
\text { Martins et al (2004) }\end{array}$ \\
\hline Liderança & $\begin{array}{l}\text { A percepção de que a liderança é exercida com base na } \\
\text { competência sendo, portanto, aceita pela organização e } \\
\text { seus membros; comportamento das chefias; aborda o } \\
\text { encorajamento pelo chefe ao desenvolvimento profissional, } \\
\text { feedback claro sobre assuntos que afetam o trabalho e } \\
\text { conversa franca sobre o desempenho pessoal. }\end{array}$ & $\begin{array}{l}\text { Modelo de Schneider (1975); } \\
\text { de Coda (1997) }\end{array}$ \\
\hline $\begin{array}{l}\text { Satisfação com o } \\
\text { trabalho }\end{array}$ & $\begin{array}{l}\text { Avaliar o quanto os retornos ofertados pela empresa em } \\
\text { forma de salários e promoção, o quanto a convivência com } \\
\text { os colegas e as chefias e o quanto a realização das tarefas } \\
\text { propiciam ao empregado sentimentos gratificantes ou } \\
\text { prazerosos. }\end{array}$ & $\begin{array}{l}\text { Modelo de Schneider (1975); } \\
\text { de Colossi (1991) }\end{array}$ \\
\hline Conflitos & Concerne à existência de grupos isolados ou fechados. & $\begin{array}{l}\text { Modelo de Litwin e Stringer } \\
\text { (1968); de Schneider (1975) }\end{array}$ \\
\hline Responsabilidade & $\begin{array}{l}\text { Grau em que as pessoas sentem que podem tomar decisões a } \\
\text { respeito do seu trabalho no intuito de atingir os objetivos da } \\
\text { organização. }\end{array}$ & $\begin{array}{l}\text { Modelo de Litwin e Stringer } \\
\text { (1968); de Schneider (1975) }\end{array}$ \\
\hline Segurança & $\begin{array}{l}\text { Avalia a sensação de segurança para a assunção de riscos } \\
\text { inerentes ao trabalho e à criação. }\end{array}$ & $\begin{array}{l}\text { Modelo de Rubbo (2002); de } \\
\text { Bispo (2006) }\end{array}$ \\
\hline $\begin{array}{l}\text { Cultura } \\
\text { Organizacional }\end{array}$ & $\begin{array}{l}\text { Expressam os valores organizacionais (cooperação, } \\
\text { poder, competição, satisfação, bem-estar) e as praticas } \\
\text { organizacionais (integração, relacionamento, recompensa, } \\
\text { treinamento). }\end{array}$ & $\begin{array}{l}\text { Modelo de Colossi (1991); de } \\
\text { Bispo (2006) }\end{array}$ \\
\hline $\begin{array}{l}\text { Sentidos do } \\
\text { Trabalho }\end{array}$ & $\begin{array}{l}\text { Vivência de gratificação profissional, orgulho, identificação } \\
\text { com o trabalho que faz, fortalecendo a constituição e } \\
\text { expressão da subjetividade. }\end{array}$ & Modelo de Coda (1997) \\
\hline
\end{tabular}

Fonte: Próprios autores (2015) 
As pesquisas avançam na discussão dos fatores que influenciam o clima organizacional, de forma que os estudos exploram aspectos estruturais e contextuais do trabalho, considerando o reconhecimento e a valorização do trabalhador, tendo o relacionamento interpessoal como um comportamento preponderante, bem como a postura de liderança. Além desses, repercute em um clima organizacional favorável a satisfação do empregado, a não existência de conflitos, a sensação de segurança e a responsabilidade. Por fim, a perspectiva dos sentidos do trabalho e da filosofia da organização, como forma de relacionar cultura organizacional com o clima.

\section{Metodologia}

A pesquisa é teórica e empírica, de abordagem quantitativa, do tipo levantamento ou survey, (RICHARDSON, 1999; COLLIS, HUSSEY, 2006), com dados coletados em uma amostra probabilística da população dos funcionários de uma indústria de higiene pessoal, perfumaria e cosméticos.

A literatura aponta uma multiplicidade de modelos de clima organizacional, com variadas dimensões, que buscam apreender o fenômeno por meio da percepção dos sujeitos envolvidos com as organizações.

Tendo em vista a reunião das dimensões mais estudadas, a pesquisa optou pelo levantamento de variáveis que representassem os constructos comuns entre os pesquisadores sobre o tema, numa perspectiva de ampliar o estudo para os principais aspectos abordados pelos modelos de clima organizacional, os quais foram complementados pelos funcionários do Departamento de Recursos Humanos da empresa objeto de estudo que analisaram o roteiro de perguntas e fizeram acréscimos e exclusões. As dimensões explicativas do clima organizacional e as variáveis da pesquisa estão apresentadas no quadro 3.

Quadro 3 . Dimensões explicativas do Clima Organizacional

\begin{tabular}{|l|l|l|}
\hline \multicolumn{1}{|c|}{ Dimensões } & \multicolumn{1}{|c|}{ Modelos } & \multicolumn{1}{c|}{ Variáveis da pesquisa } \\
\hline Conforto físico & $\begin{array}{l}\text { Modelo de Litwin e Stringer } \\
\text { (1968); Modelo de Schneider } \\
\text { (1975); Modelo de Bispo (2006); } \\
\text { Modelo de Colossi (1991); Modelo } \\
\text { de Martins et al (2004) }\end{array}$ & $\begin{array}{l}\text { Eu tenho os equipamentos, máquinas, ferramentas e EPIs } \\
\text { necessários para realizar meu trabalho. }\end{array}$ \\
\hline $\begin{array}{l}\text { Reconhecimento } \\
\text { e Valorização }\end{array}$ & $\begin{array}{l}\text { Modelo de Coda (1997); Modelo } \\
\text { de Rubbo (2002); Modelo de } \\
\text { Coda (1997) }\end{array}$ & $\begin{array}{l}\text { Aqui existe consideração pela minha pessoa independente } \\
\text { da minha função na empresa. }\end{array}$ \\
\hline $\begin{array}{l}\text { Coesão entre } \\
\text { colegas }\end{array}$ & $\begin{array}{l}\text { Modelo de Litwin e Stringer } \\
\text { (1968); Modelo de Coda (1997); }\end{array}$ & $\begin{array}{l}\text { Existe um bom relacionamento entre as lideranças (chefes } \\
\text { e encarregados) da empresa. } \\
\text { Você tem um bom relacionamento com o Diretor da sua } \\
\text { área. } \\
\text { Existe um sentimento de “equipe" na empresa. }\end{array}$ \\
\hline Liderança & $\begin{array}{l}\text { Modelo de Schneider (1975); } \\
\text { Modelo de Coda (1997) }\end{array}$ & $\begin{array}{l}\text { Você sabe com clareza quem é seu líder. } \\
\text { Seu líder faz elogios e reconhece seu bom trabalho. } \\
\text { O seu líder deixa claro o que ele espera de seu trabalho. } \\
\text { O seu líder é comprometido com as metas da empresa. } \\
\text { Sempre que você erra o seu líder lhe ensina a fazer o certo. } \\
\text { O seu líder tem uma visão clara do rumo (futuro da } \\
\text { Empresa) e o que fazer para chegar lá. } \\
\text { O seu líder confia no trabalho da equipe. } \\
\text { Você alguma vez foi humilhado pelo seu líder ou por } \\
\text { qualquer outra pessoa da empresa. }\end{array}$ \\
\hline
\end{tabular}




\begin{tabular}{|l|l|l|}
\hline $\begin{array}{l}\text { Satisfação com o } \\
\text { trabalho }\end{array}$ & $\begin{array}{l}\text { Modelo de Schneider (1975); } \\
\text { Modelo de Colossi (1991) }\end{array}$ & $\begin{array}{l}\text { Você está satisfeito com o serviço prestado pelo refeitório } \\
\text { da empresa. } \\
\text { Você está satisfeito com os benefícios da empresa. } \\
\text { Pretendo continuar trabalhando aqui por vários anos. }\end{array}$ \\
\hline Conflitos & $\begin{array}{l}\text { Modelo de Litwin e Stringer (1968); } \\
\text { Modelo de Schneider (1975) }\end{array}$ & $\begin{array}{l}\text { Existe preconceito na empresa com relação a sexo, raça, } \\
\text { cor, religião ou situação financeira. }\end{array}$ \\
\hline Responsabilidade & $\begin{array}{l}\text { Modelo de Litwin e Stringer (1968); } \\
\text { Modelo de Schneider (1975) }\end{array}$ & $\begin{array}{l}\text { As pessoas aqui tem vontade e se empenham para realizar } \\
\text { o seu trabalho. Eu me sinto responsável pela limpeza e } \\
\text { higiene da empresa. }\end{array}$ \\
\hline Segurança & $\begin{array}{l}\text { Modelo de Rubbo (2002); Modelo } \\
\text { de Bispo (2006) }\end{array}$ & $\begin{array}{l}\text { Este é um lugar fisicamente (instalações da empresa e do } \\
\text { setor) seguro para se trabalhar. }\end{array}$ \\
\hline $\begin{array}{l}\text { Cultura } \\
\text { Trabalho }\end{array}$ & Modelo de Colossi (1991); Modelo & $\begin{array}{l}\text { Você percebe que a Presidência e a Diretoria da empresa } \\
\text { buscam melhorias para seus colaboradores. }\end{array}$ \\
\hline
\end{tabular}

Fonte: Dados da Pesquisa (2015)

A escala foi aplicada neste estudo de forma pessoal a cada sujeito da amostra e, por meio de formulário eletrônico elaborado no Google Docs, enviado por e-mail. Os dados foram coletados por meio de visitas dos pesquisadores à empresa, com o consentimento prévio e apoio da equipe dirigente. Para a tabulação foi utilizada planilha Excel que foi importada para o software Statistical Package for the Social Sciences (SPSS), versão 20. Contou-se com a participação de 209 respondentes. Aos sujeitos respondentes foi informado o objetivo da pesquisa, bem como a garantia de sigilo das respostas. Tentou-se realizar senso com todos os funcionários, contudo, devido a situações específicas de alguns deles, como férias, viagens de trabalho, licença saúde, licença maternidade e a impossibilidade de alguns funcionários se ausentarem do trabalho, devido à natureza das tarefas que executa, o questionário foi então aplicado com 209 funcionários.

Aplicou-se o Alfa de Cronbach, índice estatístico que quantifica, numa escala de 0 a 1 , a confiabilidade de um questionário (HAIR et al., 2009; RODRIGUES; PAULO, 2009). O Alfa de Cronbach mede a confiabilidade do tipo consistência interna de uma escala, ou seja, avalia a magnitude em que os itens de um instrumento estão correlacionados (CORTINA, 1993). O valor mínimo aceitável para o alfa é 0,70; abaixo desse valor a consistência interna da escala utilizada é considerada baixa (STREINER; 2003). Em contrapartida, o valor máximo esperado é 0,90; acima deste valor, pode-se considerar que há redundância ou duplicação, ou seja, vários itens estão medindo exatamente o mesmo elemento de um constructo; portanto, os itens redundantes devem ser eliminados. Usualmente, são preferidos valores de alfa entre 0,80 e 0,90 (HAIR et al., 2009).

A margem de erro utilizada para o presente estudo é de 5\% (0,05), conferindo 95\% de confiabilidade. Esse percentual é utilizado com maior frequência, mesmo que seja possível escolher valores entre 3\% e 10\%, dependendo do questionário (STEVENSON, 2001).

A pesquisa teve uma proporção de 8,36 respondentes por variável, considerando 209 respondentes para 25 variáveis. Esse quantitativo amostral atende a recomendação de Hair et al. (2009), que sugere o mínimo aceitável de cinco vezes mais observações do que o número de variáveis e amostras maiores que 100 observações.

Dessa forma, o estudo quantitativo foi realizado com suporte na Análise Fatorial Exploratória (AFE), ferramenta utilizada para decifrar padrões determinantes quando o pesquisador possui um grande número de variáveis (BABBIE, 1999), considerando os resultados dos testes Kaiser-Meyer-Okin (KMO) e o de esfericidade de Bartlett, Scree Plot, Rotated Commponente Matrix (HAIR et al. 2009). 
A AFE consiste no exame das relações entre as variáveis, utilizando o coeficiente de correlação como medida de associação entre cada par de variáveis. A matriz de correlações pode permitir identificar subconjuntos de variáveis que estão muito correlacionadas entre si no interior de cada subconjunto, mas pouco associados a variáveis de outros subconjuntos. Neste caso, a aplicação da AFE permite concluir se é possível explicar este padrão de correlações por meio de um menor número de variáveis - os fatores (FIGUEIREDO FILHO; SILVA JUNIOR, 2010).

Para identificação das cargas fatoriais significantes utilizou-se a avaliação da significância estatística, que se baseia no tamanho da amostra, e também, conferiuse os valores das comunalidades das variáveis. Como a amostra foi de 209 respondentes, seguindo-se o critério de Hair et al. (2009) estabeleceu-se 0,40 como carga fatorial significante para classificar a distribuição das variáveis entre os fatores.

As comunalidades representam a proporção da variância para cada variável incluída na análise que é explicada pelos componentes extraídos. Usualmente o valor mínimo aceitável é de 0,5 (BEZERRA; 2009). Logo, caso o pesquisador encontre alguma comunalidade abaixo desse patamar a variável deve ser excluída e a AFE deve ser realizada novamente. Além disso, baixa comunalidade entre um grupo de variáveis é um indício de que elas não estão linearmente correlacionadas e, por isso, não devem ser incluídas na AFE (HAIR et al, 2009).

O planejamento da AFE ocorreu pelos seguintes estágios: análise estatística descritiva das variáveis, o tipo de extração: componente principal, tipo de rotação ortogonal pelo método Varimax. Foi considerado um padrão de correlação entre as variáveis com valor acima de 0,5 .

\section{Resultados}

A análise foi realizada em três momentos. Inicialmente, o questionário foi elaborado com 35 itens, contudo, com a obtenção de Alfa de Cronbach acima de 0,90 identificou-se indícios de duplicidade de variáveis, gerando análise de redundância de sentido dos itens e consequente exclusão das variáveis repetidas e a realização de nova AFE.

Em seguida, a primeira AFE realizada, indicou a presença de seis fatores, formados por 25 variáveis. Entretanto, a análise das comunalidades indicou a necessidade de extração de três variáveis do estudo e uma segunda AFE foi realizada. Por fim, o modelo resultante obtido foi formado com 22 variáveis representativas do Clima Organizacional por meio de 6 fatores. Desta forma, acredita-se ter chegado a um grau de relacionamento e explicação das variáveis capaz de ser útil na análise do clima organizacional, conforme está disposto nas seções Resultados e Discussão.

Em relação à segunda $\mathrm{AFE}$, os resultados dos testes KMO e o de esfericidade de Bartlett (tabela 1) e da AFE (tabela 2) explicitam informações sobre o teste do modelo em estudo, de acordo com a discussão apresentada a seguir.

Tabela 1. Testes KMO e o de esfericidade de Bartlett KMO and Bartlett's Test

\begin{tabular}{l|l|r}
\hline \multirow{2}{*}{$\begin{array}{l}\text { Kaiser-Meyer-Olkin Measure } \\
\text { of Sampling Adequacy. }\end{array}$} &, 876 \\
\hline \multirow{3}{*}{$\begin{array}{l}\text { Bartlett's Test } \\
\text { of Sphericity }\end{array}$} & Approx. Chi-Square & 1830,408 \\
\cline { 2 - 3 } & df & 231 \\
\cline { 2 - 3 } & Sig. &, 000 \\
\hline
\end{tabular}

Fonte: Dados da Pesquisa (2015)

Algumas estatísticas formais servem para testar a conveniência do modelo Fatorial (MALHOTRA, 2012). O teste de esfericidade de Barlett (BTS), por exemplo, demonstra se o valor elevado dessa estatística de teste favorece a rejeição da hipótese nula. Além disso, o teste indica se existe relação suficiente entre os indicadores para aplicação da AF (BEZERRA, 2012). A estatística qui-quadrado aproximada, observada na Tabela 1, é de 1830,408 com 231 graus de liberdade, significativa ao nível de 0,000 . Para que seja possível a AFE, recomenda-se que o valor de Sig. (teste de significância) não ultrapasse 0,05 (BEZERRA, 2012).

A medida de adequação da amostra de KMO é um índice que compara as magnitudes dos coeficientes de correção observados com as magnitudes dos coeficientes de correlação parcial. Pequenos valores da estatística KMO indicam que as correlações entre pares de variáveis não podem ser explicadas por outras variáveis e que a AFE pode ser inapropriada (MALHOTRA, 2012).

O valor do KMO da amostra é de 0,876 , ou seja, 
superior ao patamar crítico de 0,70 , ressaltando que a amostra possui correlações entre pares de variáveis que podem ser explicadas por outras variáveis. Da mesma forma, o teste BTS é estatisticamente significante $(\mathrm{p}<0,05)$. Em ambos os casos, os testes sugerem que os dados são adequados à AFE. O passo seguinte é determinar o número de fatores que serão extraídos (Tabela 2).

Tabela 2. Determinação do total de fatores representantes das variáveis de Clima Organizacional

\begin{tabular}{|c|c|c|c|c|c|c|c|c|c|}
\hline \multicolumn{10}{|c|}{ Total Variance Explained } \\
\hline \multirow{2}{*}{ Component } & \multicolumn{3}{|c|}{ Initial Eigenvalues } & \multicolumn{3}{|c|}{$\begin{array}{c}\text { Extraction Sums of Squared } \\
\text { Loadings }\end{array}$} & \multicolumn{3}{|c|}{$\begin{array}{c}\text { Rotation Sums of Squared } \\
\text { Loadings }\end{array}$} \\
\hline & Total & $\begin{array}{c}\% \text { of } \\
\text { Variance }\end{array}$ & $\begin{array}{c}\text { Cumulative } \\
\%\end{array}$ & Total & $\begin{array}{c}\% \text { of } \\
\text { Variance }\end{array}$ & $\begin{array}{c}\text { Cumulative } \\
\%\end{array}$ & Total & $\begin{array}{c}\% \text { of } \\
\text { Variance }\end{array}$ & $\begin{array}{c}\text { Cumulative } \\
\%\end{array}$ \\
\hline 1 & 7,546 & 34,300 & 34,300 & 7,546 & 34,300 & 34,300 & 3,074 & 13,972 & 13,972 \\
\hline 2 & 1,696 & 7,709 & 42,009 & 1,696 & 7,709 & 42,009 & 2,691 & 12,230 & 26,202 \\
\hline 3 & 1,410 & 6,409 & 48,419 & 1,410 & 6,409 & 48,419 & 2,599 & 11,813 & 38,015 \\
\hline 4 & 1,264 & 5,747 & 54,165 & 1,264 & 5,747 & 54,165 & 2,524 & 11,471 & 49,486 \\
\hline 5 & 1,128 & 5,126 & 59,292 & 1,128 & 5,126 & 59,292 & 1,957 & 8,895 & 58,380 \\
\hline 6 & 1,039 & 4,723 & 64,014 & 1,039 & 4,723 & 64,014 & 1,240 & 5,634 & 64,014 \\
\hline 7 &, 792 & 3,599 & 67,614 & & & & & & \\
\hline 8 &, 765 & 3,479 & 71,093 & & & & & & \\
\hline 9 &, 727 & 3,306 & 74,399 & & & & & & \\
\hline 10 & 670 & 3,047 & 77,446 & & & & & & \\
\hline 11 & ,627 & 2,851 & 80,297 & & & & & & \\
\hline 12 &, 593 & 2,693 & 82,990 & & & & & & \\
\hline 13 &, 582 & 2,645 & 85,635 & & & & & & \\
\hline 14 &, 542 & 2,466 & 88,101 & & & & & & \\
\hline 15 & ,460 & 2,093 & 90,193 & & & & & & \\
\hline 16 & ,416 & 1,893 & 92,086 & & & & & & \\
\hline 17 &, 374 & 1,700 & 93,786 & & & & & & \\
\hline 18 & ,330 & 1,498 & 95,285 & & & & & & \\
\hline 19 &, 307 & 1,397 & 96,682 & & & & & & \\
\hline 20 & ,274 & 1,244 & 97,926 & & & & & & \\
\hline 21 & ,232 & 1,056 & 98,982 & & & & & & \\
\hline 22 & ,224 & 1,018 & 100,000 & & & & & & \\
\hline
\end{tabular}

Extraction Method: Principal Component Analysis.

Fonte: Dados da Pesquisa (2015)

A técnica mais comumente usada para se definir o número de fatores a extrair é o critério da raiz latente (HAIR et al. 2009; MALHOTRA, 2012). Apenas fatores que têm raízes latentes ou autovalores acima de 1,0 são considerados significantes, o que indica a existência de 6 fatores (tabela 2) para explicar as variáveis investigadas. Além disso, considera-se o percentual mínimo de explicação da variância apropriado o valor de $60 \%$, embora se aceite valores menores nas ciências sociais, em função da peculiaridade da área, composta por informações nem sempre precisas (HAIR et al. 2009). Os dados sugerem que 6 fatores conseguem explicar 64,014\% das variáveis.

Para confirmar 6 fatores utilizou-se o teste scree (Gráfico 1), que permite identificar o número ótimo de fatores que podem ser extraídos antes que a quantia de variância única comece a dominar a estrutura de variância comum (HAIR et al. 2009). 
Gráfico 1. Scree Plot dos fatores de Clima Organizacional

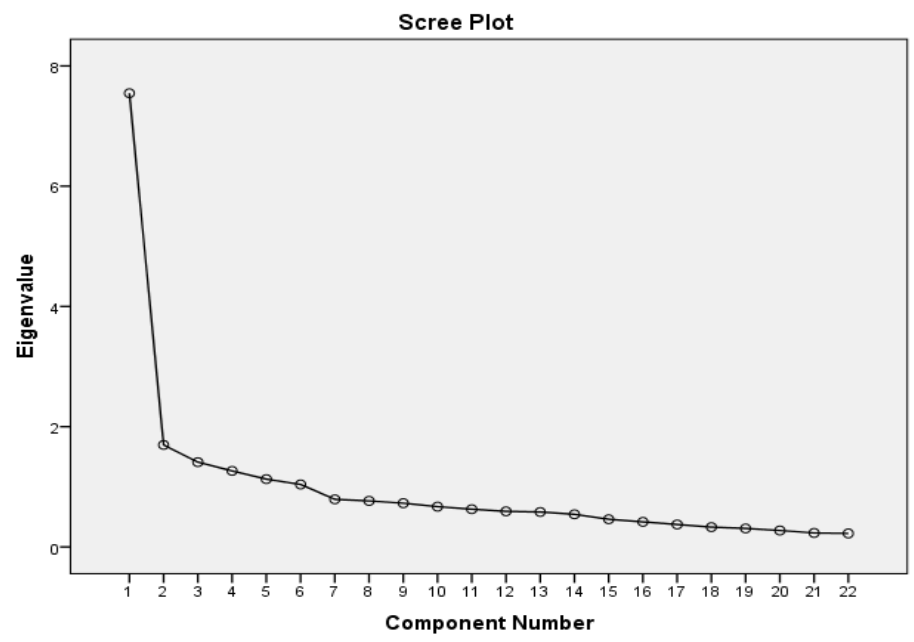

Fonte: Dados da Pesquisa (2015)

O gráfico 1 indica o valor demostrado pela tabela 2, confirmando os 6 fatores. Para avaliar a confiabilidade da pesquisa utilizou-se o Alfa de Cronbach para medir a confiabilidade da escala estudada (HAIR et al., 2009).

Dessa forma, verifica-se na Tabela 3 que o Alfa de Cronbach é 0,867, com base em 22 variáveis. Notam-se valores consistentes que demonstram elevada análise de confiabilidade. Os indicadores de comunalidades não indicaram a necessidade de extração de variáveis, pois todas apresentaram valores acima de 0,50.

Tabela 3 . Teste de confiabilidade

Reliability Statistics

\begin{tabular}{c|c}
\hline Cronbach's Alpha & N. of Items \\
\hline, 867 & 22 \\
\hline
\end{tabular}

Fonte: Dados da Pesquisa (2015)

As informações da tabela 4 apontam a relação entre os fatores e as variáveis, no sentido de averiguar qual dos fatores melhor explica cada um dos indicadores considerados. Observou-se em cada uma das variáveis com qual fator houve correlação mais forte, entre os 6 fatores.

Utilizou-se o método de avaliação de significância estatística para identificação de cargas fatoriais significantes com base no tamanho da amostra, proposto por Hair et al. (2009). As cargas fatoriais iguais ou superiores 0,40 estão marcadas na tabela 4. Há que se notar que há variáveis com mais de uma carga fatorial relevante.

Tabela 4 . Matriz rotacionada dos componentes dos fatores de Clima Organizacional.

\section{Rotated Component Matrix}

\begin{tabular}{|c|c|c|c|c|c|c|}
\hline & \multicolumn{6}{|c|}{ Component } \\
\hline & 1 & 2 & 3 & 4 & 5 & 6 \\
\hline $\begin{array}{l}\text { 1. Eu tenho os equipamentos, máquinas, ferramentas e EPIs } \\
\text { necessários para realizar meu trabalho. }\end{array}$ & , 185 & ,164 & ,711 &,- 003 & , 100 & ,085 \\
\hline
\end{tabular}


2. Este é um lugar fisicamente (instalações da empresa e do setor) seguro para se trabalhar.

3. Você sabe com clareza quem é seu líder.

4. Seu líder faz elogios e reconhece seu bom trabalho.

5. Você considera seu líder um exemplo a ser seguido.

6. O seu líder deixa claro o que ele espera de seu trabalho.

7. O seu líder é comprometido com as metas da empresa.

8. Sempre que você erra o seu líder lhe ensina a fazer o certo.

9. O seu líder tem uma visão clara do rumo (futuro da Empresa) e o que fazer para chegar lá.

10. O seu líder confia no trabalho da equipe.

11. Você alguma vez foi humilhado pelo seu líder ou por qualquer outra pessoa da empresa.

12. Você percebe que a Presidência e a Diretoria da empresa buscam melhorias para seus colaboradores.

13. Existe um sentimento de "equipe" na empresa.

14. Aqui existe consideração pela minha pessoa independente da minha função na empresa.

15. As pessoas aqui tem vontade e se empenham para realizar o seu trabalho.

16. Meu trabalho tem um sentido especial, para mim, não é só "mais um emprego".

17. Quando você foi admitido fizeram você se sentir bem-vindo.

18. Tenho orgulho de contar a outras pessoas que trabalho aqui.

19. Existe preconceito na empresa com relação a sexo, raça, cor, religião ou situação financeira.

20. Eu me sinto responsável pela limpeza e higiene da empresa.

21. Você está satisfeito com os benefícios da empresa.

22. Pretendo continuar trabalhando aqui por vários anos.

\begin{tabular}{|c|c|c|c|c|c|}
\hline ,118 & 151 & 629, & 189, &,- 142 &,- 256 \\
\hline, 336 &,- 005 & ,172 & ,051 & ,715 &,- 118 \\
\hline 431 & 234 & ,359 & 110, & ,534 & 107, \\
\hline, 598 & ,201 & ,077 & ,094 & ,488 &,- 072 \\
\hline ,784 & ,085 & ,029 & ,210 & ,156 &,- 170 \\
\hline 612, & ,476 & -144 & 165, &,- 056 & ,007 \\
\hline 680, & ,001 & 392 & 169, & 146, & 037, \\
\hline 603, & ,346 & ,276 & ,105 & ,029 & 008 \\
\hline ,530 & ,063, & 448, & 047, & 211 & ,086 \\
\hline ,000 &,- 388 & 135, & 133 &,- 491 & 419, \\
\hline ,080 & ,327 & 626, & 219, & 239, & -155 \\
\hline 235 & 651 & ,273 & 228 & 080 & 094 \\
\hline 164 & ,730 & 249 & 215 & 195, &,- 028 \\
\hline 113, & 690 & 164 & 142 & 020 &,- 029 \\
\hline 213 & ,129 & 189, & ,720 &,- 033 & 081, \\
\hline ,254 & ,185 & ,004 & ,741 &,- 046 &,- 202 \\
\hline 158 & 298 & 277 & 672 & ,069, &,- 110 \\
\hline,- 046 & ,047 & -144 &,- 064 &,- 071 & 869, \\
\hline,- 095 & ,083 &,- 034 & ,624 & ,470 & ,176 \\
\hline ,064 & ,392 & 467, & 296 & ,356 &,- 206 \\
\hline 142, & 444 & ,394 & 409, & 307, &,- 016 \\
\hline
\end{tabular}

Extraction Method: Principal Component Analysis.

Rotation Method: Varimax with Kaiser Normalization.

a. Rotation converged in 15 iterations.

Fonte: Dados da pesquisa (2015)

A matriz, após a rotação dos fatores, já permite uma classificação mais precisa dos indicadores em cada um dos fatores. Após identificar em que fator cada variável tem carga fatorial significante, deve-se tentar designar algum significado para o padrão de cargas fatoriais (HAIR et al. 2009). As cargas mais altas devem ser consideradas mais importantes e ter maior influência sobre o nome ou rótulo selecionado para representar um fator. Desse modo, realizou-se a distribuição das variáveis por fator e puderam-se conceituar os fatores obtidos no estudo, os quais são apresentados na discussão. 


\section{Discussão}

Como a matriz fatorial rotacionada (Tabela 4) é a que constitui a base para a interpretação dos fatores (MALHOTRA, 2012), contatou-se que:

O fator 1 foi o mais forte, responsável por 13,97\% da variância explicada, o qual correlacionou-se fortemente com as variáveis: 5 . Você considera seu líder um exemplo a ser seguido.; 6. O seu líder deixa claro o que ele espera de seu trabalho; 7. O seu líder é comprometido com as metas da empresa; 8. Sempre que você erra o seu líder lhe ensina a fazer o certo; 9. O seu líder tem uma visão clara do rumo (futuro da Empresa) e o que fazer para chegar lá. Dessas, a que melhor representa o fator é a variável 6 .

De forma expressiva, as variáveis que compõem o primeiro fator destacaram a importância da liderança na repercussão de um clima organizacional favorável, podendo ser nomeado como "Papel do líder". Este resultado encontrado confirmou a dimensão na explicação do constructo e potencializou inferências importantes no âmbito gerencial, considerando o aspecto da influência exercida em face da confiança estabelecida (DRUMMOND, 2007). Ressalta-se que a liderança é um dos temas do comportamento organizacional mais estudado e, talvez, menos compreendido, tendo em vista o fenômeno ser entendido como parte de características a priori e, também, resultado da dinâmica organizacional (MELO, 2014). Assim, o impacto da liderança na instituição estudada informou que, a liderança é uma peça importante no emaranhado organizacional e, por meio dela, é possível desenvolver ações em prol do desenvolvimento profissional e organizacional com base na busca de realização de tarefas, com aporte na extensão do relacionamento estabelecido, diante das demandas do ambiente que são melhor administradas se o líder em questão tiver habilidade em adaptar seu estilo ao contexto situacional (SCHNEIDER, 1975; CODA,1997; MELO, 1999, 2014).

Considerando que há maior correlação da variável 6 no fator 1, o estudo apontou que na instituição, o aspecto da tarefa é preponderante, devido ao líder possuir importante papel na definição e estruturação das tarefas de seus subordinados, de forma a orientar os "aspectos técnicos da função, a observância dos padrões, os canais de comunicação, a hierarquia, os procedimentos e os métodos" (MELO, 2014, p.224) e que esse direcionamento é fator de melhoria do clima organizacional.
O fator 2, responsável por 12,23\% da variância explicada, correlacionou-se fortemente com as seguintes variáveis: 13. Existe um sentimento de "equipe" na empresa; 14. Aqui existe consideração pela minha pessoa independente da minha função na empresa; 15. As pessoas aqui tem vontade e se empenham para realizar o seu trabalho; 22. Pretendo continuar trabalhando aqui por vários anos. Dessas, a variável que melhor caracteriza o fator corresponde ao item 14.

O conjunto de variáveis do fator 2 tratou sobre o relacionamento entre funcionários, o vínculo, o compromisso com o bem estar dos colegas e com a organização. Atributos que favorecem o desejo de permanecer na instituição a longo prazo. Em consideração às variáveis elencadas no fator, sugeriu-se o rótulo "Coesão entre colegas", em consonância com os modelos de clima selecionados (LITWIN; STRINGER, 1968; CODA, 1997; MARTINS et al. 2004).

A integração entre funcionários revelou-se central no fator 2 e colaborou com o clima organizacional a medida que intensificou um ambiente amistoso e mais propício a desenvolver barreiras a aspectos nocivos ao bom relacionamento intra-organizacional, como a competitividade (MARTINS; 2008). Por sua vez, a interação harmoniosa pode produzir maior suporte organizacional, expressa pela maior competência grupal na resolução de conflitos e manifestação de necessidades coletivas. Também é perceptível que, associado a uma liderança voltada para a tarefa, em atenção às questões grupais, face à relevância dessas dimensões, o gestor da instituição em análise pode potencializar um clima organizacional mais favorável.

As variáveis melhor correlacionadas ao fator 3, responsável por $11,81 \%$ da variância explicada são: 1 . Eu tenho os equipamentos, máquinas, ferramentas e EPIs necessários para realizar meu trabalho 2. Este é um lugar fisicamente (instalações da empresa e do setor) seguro para se trabalhar. 12. Você percebe que a Presidência e a Diretoria da empresa buscam melhorias para seus colaboradores. 21. Você está satisfeito com os benefícios da empresa. Esse conjunto de assertivas indicam duas questões organizacionais importantes: o suporte físico, em referência às instalações físicas e aos equipamentos e o suporte material, caracterizado pela existência de benefícios para os trabalhadores. Assim, o fator recebe o título de "Suporte físico e material". A variável que melhor caracteriza o fator corresponde ao item 1.

Em torno do fator 3, aspectos das dimensões conforto físico (LITWIN; STRINGER, 1968; SCHNEIDER, 
1975; BISPO, 2006; COLOSSI, 1991; MARTINS et al, 2004), segurança (RUBBO, 2002; BISPO, 2006); satisfação com o trabalho (SCHNEIDER, 1975; COLOSSI,1991) e cultura (COLOSSI,1991; BISPO, 2006) devem ser investigados para definir seu sentido.

De forma geral, almeja-se que a empresa possua uma estrutura física que garanta conforto, de forma que minimize situações de estresse ocupacional, acidentes de trabalho, favorecendo sentimentos gratificantes e prazerosos em função do satisfação na execução das tarefas. Ademais, as instalações físicas e os equipamentos respondem por esse suporte que é elementar para a execução de tarefas com o menor risco à saúde e ao bem-estar dos trabalhadores. Para tanto, a cultura organizacional é preponderante para a priorização desse suporte, seja por motivos com foco no trabalhador, seja por preocupação com os rumos da empresa, ou com os dois.

O Quadro 4 sintetiza os 6 fatores identificados pela pesquisa e suas respectivas definições sugeridas pelo presente estudo.

Quadro 4 . Fatores explicativos de Clima Organizacional.

\begin{tabular}{|l|l|l|}
\hline \multicolumn{2}{|c|}{ Dimensões } & \multicolumn{1}{c|}{ Definições } \\
\hline 1 & Papel do líder & $\begin{array}{l}\text { A centralidade da liderança } \\
\text { é a essência desse fator. } \\
\text { Porém, a especificidade se } \\
\text { dá pela influência do papel } \\
\text { da liderança na orientação da } \\
\text { tarefa e em prol da adaptação } \\
\text { do perfil de gestão ao contexto } \\
\text { organizacional. }\end{array}$ \\
\hline 2 & $\begin{array}{l}\text { Os relacionamentos } \\
\text { interpessoais influenciam } \\
\text { o clima na medida em que } \\
\text { produz ao nível individual e } \\
\text { coletivo estratégias de defesa } \\
\text { diante de adversidades e aciona } \\
\text { o potencial de resolução de } \\
\text { conflitos. }\end{array}$ \\
\hline 3 & $\begin{array}{l}\text { A estrutura física e as políticas } \\
\text { de remuneração e benefícios } \\
\text { favorecem sentimentos } \\
\text { prazerosos na relação com a } \\
\text { tarefa e diante da organização, } \\
\text { em consequência do fator } \\
\text { recompensa e reconhecimento. }\end{array}$ \\
\hline
\end{tabular}

\begin{tabular}{|l|l|l|}
\hline 4 & $\begin{array}{l}\text { Bem-estar no } \\
\text { trabalho }\end{array}$ & $\begin{array}{l}\text { Sentimentos de bem-estar } \\
\text { favorecem o clima face o } \\
\text { envolvimento com o trabalho, } \\
\text { o comprometimento afetivo e } \\
\text { a satisfação diante do trabalho } \\
\text { desenvolvido. }\end{array}$ \\
\hline 5 & $\begin{array}{l}\text { A liderança, nessa dimensão, } \\
\text { assume o papel de afirmar } \\
\text { hierarquia e é lugar de exercício } \\
\text { Ho poder, aspectos que devem } \\
\text { ser ponderados para uma } \\
\text { estabelecimento de um clima } \\
\text { organizacional harmonioso. }\end{array}$ \\
\hline 6 & $\begin{array}{l}\text { Respeito à } \\
\text { diversidade }\end{array}$ & $\begin{array}{l}\text { Diante da diversidade humana } \\
\text { nas organizações, o respeito } \\
\text { nas relações interpessoais no } \\
\text { âmbito organizacional impacta } \\
\text { o clima, tendo em vista que } \\
\text { o estigma de determinadas } \\
\text { características ou perfis } \\
\text { podem resultar em atitudes de } \\
\text { preconceito e que podem gerar } \\
\text { conflitos. }\end{array}$ \\
\hline
\end{tabular}

Fonte: Dados da Pesquisa (2015)

Inferiu-se, também, que a satisfação com o trabalho seja influenciada pela política de benefícios, tendo em vista o reconhecimento do trabalho executado por meio dos retornos ofertados pela empresa em forma de salários, benefícios e, até, promoções.

O quarto fator respondeu por $11,47 \%$ da variância explicada e reuniu as variáveis: 16. Meu trabalho tem um sentido especial, para mim, não é só "mais um emprego". 17. Quando você foi admitido fizeram você se sentir bem-vindo. 18. Tenho orgulho de contar a outras pessoas que trabalho aqui. 20. Eu me sinto responsável pela limpeza e higiene da empresa. Desses itens, a maior correlação com o fator foi observada pela questão 17 .

A leitura da composição do fator 4 caracterizou aspectos de sentimento de bem estar, que triangula o envolvimento com o trabalho, a satisfação com o trabalho, e o comprometimento organizacional afetivo (SIQUEIRA, 2009). Em primeiro lugar, o envolvimento com o trabalho traduz a ideia de um trabalhador que se vincula com as tarefas, significandoas de forma pessoal, de maneira que estipula-se metas e desafios pessoais que dão contorno ao sentido 
"especial" desse trabalho. A satisfação informa que as relações interpessoais favorecem o bem-estar e geram, também, maior identificação com a organização e sentimento de pertença. O comprometimento afetivo, também em consonância com o bem-estar, provoca uma ligação afetiva com a organizacional, de forma que há maior preocupação com a empresa, manifesta pelo senso de responsabilidade cotidiana. Assim, sugere-se que o fator 4 seja dimensionado como "Bem-estar no trabalho".

A quinta dimensão foi formada pelos seguintes itens: 3. Você sabe com clareza quem é seu líder; 4. Seu líder faz elogios e reconhece seu bom trabalho. 5 . Você considera seu líder um exemplo a ser seguido. 11. Você alguma vez foi humilhado pelo seu líder ou por qualquer outra pessoa da empresa. $O$ fator explica $8,89 \%$ da variância explicada e possui maior correlação com a questão 3.

Embora os itens tenham feito referência ao aspecto da liderança, explicada como fator 1, aqui há algumas peculiaridades. Os itens apontaram a relação entre líder e liderado, como forma de reconhecimento do líder pelo liderado e reconhecimento do liderado pelo líder. Além disso, quando o líder faz uso da relação de poder posta da relação hierárquica e expõe o trabalhador de forma pejorativa, as relações se fragilizam e o clima resultante tona-se hostil. Assim, o reconhecimento ao nível da hierarquia estabelecida de forma que o líder seja um exemplo a ser seguido é fruto de uma boa convivência, onde há respeito mútuo. Para tanto, a relação amistosa estabelecida entre líderliderado converge para uma boa avaliação de clima organizacional. Assim, apostou-se no conceito "Poder e Hierarquia" como rótulo para a quinta dimensão.

Por último, os dados apontaram para o sexto fator, responsável por 5,63 \% da variância explicada. Compôs o fator apenas a variável 19 que se refere a "Existe preconceito na empresa com relação a sexo, raça, cor, religião ou situação financeira". O item expressou a posição de preconceito vivenciado, face à necessária consideração diante da diversidade humana, manifesta em qualquer contexto social. Assim, o conceito que melhor caracteriza o fator é a melhor resposta ao preconceito, ou seja, o "Respeito à diversidade". Esta encontra-se em consonância com a diversificação, cada vez mais intensa, do perfil dos trabalhadores e inclui raça, gênero, idade, história pessoal, organizacional, formação acadêmica, cargo, características pessoais de personalidade, preferência sexual, origem geográfica, tempo na instituição etc. (WENTLING; PALMA-
RIVAS, 1998). Assim, inferiu-se que a dimensão deve ser objeto de investigação, como aponta Nkomo e Cox Jr. (1999), tendo em vista sua aderência com o tema da pesquisa e sua repercussão em diversos fenômenos organizacionais.

\section{Considerações Finais}

A pesquisa teve como proposta realizar análise do clima organizacional em uma indústria no setor de cosméticos, com suporte em dimensões (Conforto físico, Reconhecimento e Valorização, Coesão entre colegas, Liderança, Satisfação com o trabalho, Conflitos, Responsabilidade, Segurança, Cultura, Sentidos do Trabalho) e variáveis levantadas por meio do aporte teórico do tema e pesquisa em variados modelos de clima organizacional (LITWIN; STRINGER, 1968; SCHNEIDER, 1975; LA FOLLETE; SIMS, 1975; SBRAGIA, 1983; KOLB et al. 1986; RIZZATTI, 1995; CODA, 1997; COLOSSI, 1991; RUBBO, 2002; MARTINS et al. 2004; BISPO, 2006).

No que tange à estatística, foi empregada Análise Fatorial Exploratória, com referência a 209 respondentes. A apreciação dos dados confirma um relacionamento consistente entre as variáveis latentes e o clima organizacional, com a formação de seis fatores com o grau de explicação do fenômeno investigado de $64 \%$ (sessenta e quatro por cento). O instrumento de medição apresentou alta confiabilidade, especificamente na indústria onde foi aplicado.

O estudo analisou a formação de seis dimensões, em ordem decrescente de importância: Papel do líder; Coesão entre colegas; Suporte físico e material; Bemestar no trabalho; Poder e Hierarquia e Respeito à diversidade.

O primeiro fator, papel do líder, teve como variável mais importante o item 6 que se refere a "O seu líder deixa claro o que ele espera de seu trabalho". Dessa forma, o papel da liderança que se configura no contexto da pesquisa repercute no aspecto de gestão do líder, no sentido de se esperar dele a orientação necessária para a organização e execução da tarefa. Nesse cenário, aponta-se a peculiaridade do trabalho industrial, em comparação com atividades que exigem maior autonomia e criatividade. $\mathrm{O}$ trabalho na indústria, em geral, é formado por atividades estruturadas e pré-definidas, o que torna a orientação para tarefa aspecto de maior importância. 
A coesão entre colegas apontou maior correlação com a variável 14 "Aqui existe consideração pela minha pessoa independente da minha função na empresa". Em sintonia com a necessária interação interpessoal para potencializar um bom clima organizacional, há ênfase no aspecto da horizontalidade. Nesse sentido, o trabalhador que se sente "igual", em que sua posição não é fator de exclusão nos relacionamentos sociais postos no contexto laboral, reponde de forma positiva ao clima, ou seja, indica que há um ambiente de trabalho harmonioso.

O terceiro fator, suporte físico e material, resultou como principal variável o item 1 que se refere a "Eu tenho os equipamentos, máquinas, ferramentas e EPIs necessários para realizar meu trabalho". Essa correlação forte indica importante consideração por parte dos trabalhadores pesquisados no que tange a estrutura física para que se possa executar de forma efetiva o trabalho. Ressalta-se, nesse ponto, o tipo de organização em estudo. A indústria possui atividades muito dependentes de equipamentos e instrumentos, sem as quais, o trabalho torna-se inviável, perigoso, ou mais complexo. Uma boa estrutura física facilita o trabalho e, possivelmente, promove maior tranquilidade na execução da tarefa. Assim, o estudo sugere um importante impacto da estrutura física e material da organização sobre o clima organizacional.

O fator quatro, bem-estar no trabalho, obteve maior correlação com a variável 17 "Quando você foi admitido fizeram você se sentir bem-vindo". Assim, a denominação "bem-estar no trabalho" é conferida em função do que o contexto suscita em relação à sensação de conforto e prazer do trabalhador que pode ser observado pelo sentimento de acolhimento, como denota o item 17. Conceber o trabalhador como parte integrante da conjuntura organizacional potencializa esse acolhimento, podendo gerar como respostas maior comprometimento, identificação e engajamento organizacional.

Outra faceta da liderança foi apontada no fator 5, poder e hierarquia, tendo como variável de maior impacto, a 3 "Você sabe com clareza quem é seu líder". Além de esperar que o líder direcione e oriente a execução da tarefa, aponta que o clima também é afetado pela relação hierárquica posta, no sentido do relacionamento direto líder-liderado. A superposição de chefias fragiliza o trabalho e torna mais complexa a interação trabalhador-organização, mediada pelo líder.
Por fim, a dimensão respeito à diversidade teve como única variável o item 19 "Existe preconceito na empresa com relação a sexo, raça, cor, religião ou situação financeira", pode ser entendido como desdobramento do fator 2 , tendo em vista que o respeito à diversidade teorizado é resultado das interações interpessoais. Sabe-se que o estigma e os pré-conceitos associados marcam novos discursos na atualidade e que as organizações precisam engajar-se nessa temática, como forma de gerir aspectos pertinentes a esse fator em sua esfera. Aponta-se, assim, que esse fator inova o conceito de clima organizacional, quando especifica aspectos das relações sociais intra-organizacionais que impactam o clima organizacional e que não respondem diretamente à ação organizacional, no sentido da execução do trabalho em si, mas é correlata à gestão, no sentido de que além dos aspectos organizacionais, a gestão lida com pessoas em suas mais variadas formas de expressão.

Conclui-se que, na organização estudada, em escala decrescente de importância, espera-se que o líder assuma papel diretivo, o que é compreensível no contexto de trabalho industrial. Além disso, anseiase por relações horizontais, em que os cargos não influenciem as interações sociais. $\mathrm{O}$ suporte físico e material, representado, pelo uso de equipamentos em condições satisfatórias é também indicativo de clima organizacional, o que é compreensível quando a tarefa tem como requisito o uso desses equipamentos. Sentir-se acolhido pela empresa é fator de bem-estar. Além disso, a hierarquia e o exercício do poder informa que a relação líder-liderado pode produzir um ambiente aversivo, quando a "equação" trabalhador-líder/chefe-organização não está bem estruturada. Por último, o aspecto da diversidade é apontado, e sugere que a gestão do clima deve ir além dos aspectos relacionados à gestão do trabalho em si, mas ampliar a leitura de contexto de trabalho no sentido de incorporar que manifestações humanas se fazem presentes no trabalho. Assim, o ser-humano não se dissocia do ser-trabalhador.

A identificação do conjunto de fatores merece maior aprofundamento teórico, de forma que as definições possam ser refletidas conceitualmente. $\mathrm{O}$ reporte à teoria limitou-se ao levantamento de dimensões em diversos modelos, sem que a pretensão fosse abranger todo o clima organizacional, mas a apreensão mais sistemática do fenômeno. 
Considera-se que a contribuição desse estudo reporta-se à revisão das dimensões teóricas do Clima Organizacional, a identificação daquelas mais pontuadas pelos principais modelos existentes e, principalmente, estruturação de um instrumento para análise do tema no âmbito industrial, haja vista que os itens consideram aspectos específicos dessa realidade. No que tange à avaliação do instrumento, recomendase apreciação dos fatores em outros contextos industriais e análise confirmatória dos achados, a fim de subsidiar a elaboração de uma escala de Clima Organizacional para o contexto industrial.

\section{Referências}

ABIHPEC - Panorama do Setor, 2014. Associação Brasileira da Indústria de Higiene Pessoal, Perfumaria e Cosméticos. Disponível em < http://www.abihpec. org.br/>. Acesso em 26 mar. 2015.

BABBIE, E. Métodos de pesquisas de survey. Belo Horizonte: UFMG,1999.

BEZERRA, F. A. Análise Fatorial. In: CORRAR, L. J, et. al (coor). Análise Multivariada: para os Cursos de Administração, Ciências Contábeis e Economia. 1. Ed, 4. Reimpr, São Paulo: Atlas, 2012.

BISPO, C. A. F.. Um novo modelo de pesquisa de clima organizacional. Produção. v. 16, n. 2, pp. 258273, 2006.

BISPO, C. A. F. Um novo modelo de pesquisa de clima organizacional. Prod., São Paulo, v. 16, n. 2, ago. 2006. Disponível em $<$ http://www.scielo.br/scielo.php?script=sci_ pid $=$ S010365132006000200007\&lng $=$ pt\&n $\mathrm{rm}=$ iso $>$. acesso em 28 mar. 2015.

\section{CHANLAT, J. F. (Org.). O indivíduo na} organização: dimensões esquecidas. Editora Atlas. São Paulo: 1996.

CODA, R. A relação entre motivação, satisfação do trabalho e administração de RH, IN: BERGAMINI, C. W.; CODA, R. (Org.) Psicodinâmica da Vida Organizacional: motivação e liderança. São Paulo: Atlas, 1997.

\section{COLLIS, J.; HUSSEY, R. Pesquisa em}

administração: um guia prático para os alunos de graduação e pós-graduação. 2. ed. Porto Alegre: Bookman, 2006.
COLOSSI, Nelson. Clima organizacional.

Florianópolis: CPGA/UFSC, 1991. Texto de uso CPGA/UFSC.

CORRAR, Luiz João; PAULO, Edilson; DIAS FILHO, José Maria (Coordenadores). Análise

multivariada para os cursos de Administração, Ciências Contábeis e Economia. 1. ed. São

Paulo: Editora Atlas, 2009, v. 1, p. 1-72.

CORTINA, J. M. What is coefficient alpha? An examination of theory and applications. Journal of Applied Psychology. v. 78, p. 98-104. 1993.

DUNNETIE, M. D. (ed.). Handbook of industrial and organizational psychology. Chicago: Rand McNally, 1976.

FIGUEIREDO FILHO, D. B.; SILVA Jr., J. A. da. Visão além do alcance: uma introdução à análise fatorial. Opin. Publica, Campinas, v.16, n.1, p. 160$185,2010$.

HAIR, J. et al. Análise Multivariada de Dados. Tradução Adonai Schlup Sant Ánna e Alselmo Chaves Neto. 6. ed. Porto Alegre: Bookman, 2009.

HAIR JR., J.F;; WILLIAM, B.; BABIN, B.; ANDERSON, R.E. Análise multivariada de dados. 6.ed. Porto Alegre: Bookman, 2009.

KEILA CRISTINA \& SOUSA, MARÍLIA R. DE. Construção e validação de uma escala de medida de clima organizacional. Psicologia: Organizações e Trabalho, v. 4, n. 1, p. 37-60, Brasília, janeiro/junho, 2004.

KOLB, David A. et al. Psicologia organizacional: uma abordagem vivencial. São Paulo: Atlas, 1986.

LA FOLLETE, W. R., SIMS, H. P. Is satisfaction redundant with organizational

climate? Organizational Behavior and Human Performance. 1975.

LEWIN, K.; LIPPITT, R. \& WHITE, R. (1939). Patterns of aggressive behaviors in experimentally created social climates. Journal of Social

Psychology, 10, 271- 299.

LITWIN, G. H., STRINGER, R. A. Motivation and organizational climate. Cambridge: Harvard University Press, 1968. 
LUZ, J. P. da. Metodologia para análise de clima organizacional: um estudo de caso para o Banco do Estado de Santa Catarina. Florianópolis: UFSC, 2001. Dissertação (Programa de Pós-Graduação em Engenharia de Produção), Universidade Federal de Santa Catarina, 2001. Disponível em: Acesso em 5 de mar. 2015

MALHOTRA, N. K. Pesquisa de Marketing. Uma orientação aplicada. Tradução de Lene Belon Ribeiro, Monica Stefani. 6. ed. Porto Alegre: Bookman, 2012

MARTINS, Maria do Carmo F; OLIVEIRA, Beatriz de; SILVA, Carliene F. da; PEREIRA,

MARTINS, Maria do Carmo Fernandes. Clima organizacional. In: SIQUEIRA, Mirlene Maria Matias. Medidas do comportamento organizacional: ferramentas de diagnóstico e de gestão. Porto Alegre: Artmed, 2008. p. 29-40.

MASLOW, A. H. Motivation and personality, New York, Harper, 1954.

MELO, E. A. A. Comportamento gerencial: levantamento de percepções. Instituto de Psicologia da Universidade de Brasilia: Brasilia, 1999.

MELO, E. A. A. Liderança Gerencial. In: SIQUEIRA, M. M. M. (Org.). Novas medidas do comportamento organizacional: ferramentas de diagnóstico e de gestão.. Artmed: Porto Alegre, 2014.

MENEZES, I.G.; GOMES, A. C. P. Clima organizacional: uma revisão histórica do construto. Psicol. rev. (Belo Horizonte), Belo Horizonte, v. 16, n. 1, abr. 2010. Disponível em $<$ http://pepsic.bvsalud.org/scielo.php?script $=$ sci_ arttext\&pid=S1677-11682010000100011\&lng=pt\&n rm=iso >. acessos em 09 maio 2015.

NKOMO, S.; COX, T. Diversidade e Identidade nas Organizações. Modelos de análises e novas questões em estudos organizacionais. In: CLEGG, S. at al. Handbook de pesquisas organizacionais. São Paulo: Atlas, 2010. v. 1

PAYNE， R. L.; MANSFIELD, R. Relationship of perceptions of organizational climate to organizational structure, context e hierarchical position. Administrative Science Quarterly, n. 18, p. 515-526, 1973.

PUENTE-PALACIOS, K. E. Abordagens teóricas e dimensões empíricas do conceito de clima organizacional. Revista de Administração, v. 37, n. 3, p. 96 - 104, jul./set. 2002.

RICHARDSON, R. Pesquisa social: métodos e técnicas. 3. ed. São Paulo, Atlas, 1999.

RIZZATTI. Gerson. Análise de fatores significativos do clima organizacional da UFSC: contribuição para implantação do programa de qualidade. 1995. Dissertação (Mestrado em Administração) Programa de Pós-Graduação em Administração, Universidade Federal de Santa Catarina, Florianópolis.

RIZZATTI, G. Categorias de análise de clima organizacional em universidades federais brasileiras. Florianópolis, 2002. Tese (Doutorado). Departamento de Engenharia de Produção e Sistemas, Universidade Federal de Santa Catarina.

RODRIGUES, A.; PAULO, E.. Introdução à Análise Multivariada. In:

RODRIGUES, L. G.; NASCIMENTO, Thiago Gomes; NEIVA, Elaine Rabelo. Valores Organizacionais e Atitudes Frente à Mudança: o Caso da Polícia Militar do Distrito Federal. Psicol. cienc. prof., Brasília, v. 34, n. 3, p. 574-591, set. 2014. Disponível em <http://www.scielo.br/ scielo.php?script $=$ sci_arttext\&pid $=$ S1414$98932014000300574 \& \operatorname{lng}=$ pt\&nrm $=$ iso $>$. acessos em 29 jul. 2015. http://dx.doi.org/10.1590/19823703000502013.

RUBBO, E. Fatores do clima organizacional que são motivadores para a inovação

tecnológica em um centro de tecnologia.

Dissertação de Mestrado. Universidade Federa do Rio Grande do Sul - Escola de Administração. Orientador: Prof. Ivan Antônio Pinheiro. 2002.

RUCHINSKI, P. R. F. Clima organizacional do planejamento estratégico corporativo: estratégia na obtenção de resultados. Cad. Pesq. NPGA, 3. p. 1-12, 2006

SANTOS, Juliana Neves; NEIVA, Elaine Rabelo; ANDRADE-MELO, Eleuni Antônio. Relação entre Clima Organizacional, Percepção de Mudança organizacional e Satisfação do Cliente. Psic.: Teor. e Pesq., Brasília, Jan-Mar 2013, Vol. 29 n. 1, pp. 31-39.

SCHNEIDER, B. Organizacional behavior: Annual Review of Psychology, Palo Alto, CA, v. 36, 1985. 
SBRAGIA, R. Um estudo empírico sobre clima organizacional em instituições de pesquisa. Revista de Administração. São Paulo, v. 18, n. 2, p. 30-9, jun. 1983.

SCHNEIDER, B. Organizational climate: an essay, personnel psychology, 28, 447-479, 1975.

SCHNEIDER, B. Organizational climate: individual preference and organizational

realities. Journal of Applied Psychology, v. 56, p. 211217, 1975. Disponível em < http:/ / files.eric.ed.gov/ fulltext/ED097528.pdf> Acesso em 11 set. 2015.

SCHNEIDER, B.; REICHERS, A. E. On the etiology of climates. Personnel Psychology,n.36, p. 19-39, 1983.

SIQUEIRA, Mirlene Maria Matias (Org.) et al.

Medidas do comportamento organizacional:

ferramentas de diagnóstico e de gestão. Porto Alegre: Artmed, 2008.

STEVENSON, W. J. Administração das

Operações de Produção. Rio de Janeiro:

LTC, 2001.

STREINER, D. L. Being inconsistent about consistency: when coefficient alpha does and doesn't matter. Journal of Personality Assessment. v. 80, p. 217-222. 2003.

TAMAYO, A. Valores e clima organizacional. ln: PAZ, M. G. T.; TAMAYO, A. (Orgs). Escola, saúde mental e trabalho.Brasilia: Editora UnB, 1999. p. 241 269.

JAMES, L. R.; JONES, A. P. Organizational climate: a review of theory and research. Organizational

Behavior and Human Performance, n. 10, p. 118144, 1974.

TORRES, E. F.; OLIVEIRA, J. A. A influência do clima organizacional no alcance da efetividade organizacional em industrias do setor alimentícios utilizando o modelo ASH. Rio de Janeiro-RJ, 2007. Disponível em: Andlt; http://www.anpad.org. brAndgt;

TORO, F. A. El clima organizacional perfil de empresas colombianas. Medellín: Cicel Ltda., 2001.
WENTLING, R. M.; PALMA-RIVAS, N. Current status and future trends of diversity initiatives in the workplace: diversity experts' perspective.

Human Resource Development Quarterly, v. 9, n. 3, p. 35-61, 1998

\section{ZANELLI, J. SILVA, N. Interação Humana e}

Gestão: a construção psicossocial das organizações de trabalho. São Paulo: Casa do Psicólogo, 2008. 